\title{
Quantifying the added value of climate information in a spatio-temporal dengue model
}

Rachel Lowe $^{1 *}$, Bernard Cazelles ${ }^{2,3}$, Richard Paul $^{4,5}$, Xavier Rodó $^{1,6}$

1. Institut Català de Ciències del Clima (IC3), Barcelona, Catalonia, Spain.

2. Université Pierre et Marie Curie, Unité de Modélisation Mathématique et Informatique des Systèmes Complexes, Campus des Cordeliers, 75270 Paris cedex 06, France.

3. Ecole Normale Supérieure, IBENS UMR 8197, Eco-Evolution Mathématique, 46 rue d'Ulm, 75230 Paris cedex 05, France.

4. Institut Pasteur, Unité de la Génétique Fonctionnelle des Maladies Infectieuses, 28 rue du Docteur Roux, F-75724, Paris cedex 15, France.

5. Centre National de la Recherche Scientifique, Unité de Recherche Associée 3012, F-75724 Paris CEDEX 15, France.

6. Institució Catalana de Recerca i Estudis Avançats (ICREA), Barcelona, Catalonia, Spain.

*Correspondence to: Dr Rachel Lowe, Climate Dynamics and Impacts Unit, Institut Català de Ciències del Clima (IC3), Doctor Trueta 203, 3a, 08005 Barcelona, Spain, Tel: +34 935679977 Fax: +34 933097600 Email: rachel.lowe@ic3.cat (not longer at this address)

Dr Rachel Lowe, Department of Infectious Disease Epidemiology, London School of Hygiene \& Tropical Medicine, Keppel Street, London WC1E 7HT, UK, Tel: +44 (0) 2079588229 Email: rachel.lowe@1shtm.ac.uk

\section{Cite this article as:}

Lowe, R., Cazelles, B., Paul, R. Rodó, X. Stoch Environ Res Risk Assess (2016) 30: 2067. doi:10.1007/s00477-015-1053-1

For the Article PDF please visit http://link.springer.com/article/10.1007/s00477-015-1053-1 


\begin{abstract}
Dengue is the world's most important vector-borne viral disease. The dengue mosquito and virus are sensitive to climate variability and change. Temperature, humidity and precipitation influence mosquito biology, abundance and habitat, and the virus replication speed. In this study, we develop a modelling procedure to quantify the added value of including climate information in a dengue model for the 76 provinces of Thailand, from 1982-2013. We first developed a seasonal-spatial model, to account for dependency structures from one month to the next and between provinces. We then tested precipitation and temperature variables at varying time lags, using linear and nonlinear functional forms, to determine an optimum combination of time lags to describe dengue relative risk. Model parameters were estimated using Integrated Nested Laplace Approximation (INLA). This approach provides a novel opportunity to perform model selection in a Bayesian framework, while accounting for underlying spatial and temporal dependency structures and linear or nonlinear functional forms. We quantified the additional variation explained by interannual climate variations, above that provided by the seasonal-spatial model. Overall, an additional $8 \%$ of the variance in dengue relative risk can be explained by accounting for interannual variations in precipitation and temperature in the previous month. The inclusion of nonlinear functions of climate in the model framework improved the model for $79 \%$ of the provinces. Therefore, climate forecast information could significantly contribute to a national dengue early warning system in Thailand.
\end{abstract}

\title{
Keywords
}

Dengue; climate; spatio-temporal model; random effects; nonlinear.

\section{Introduction}

Dengue is an emerging vector-borne viral disease, ubiquitous in the tropics and the subtropics, particularly in Southeast Asia, the Pacific and the Americas (Guzman et al., 2010). The geographic distribution of dengue and its more severe form, dengue haemorrhagic fever, has expanded dramatically in the last decades and dengue is now considered to be the world's most important arboviral disease (Gubler, 2002; Halstead, 2007). Its recent expansion has been attributed to a combination of uncontrolled urbanization, poor living conditions, increased international travel and trade (Gubler, 2012), which act as mechanisms for transporting and exchanging dengue vectors and viruses between endemic populations. The principal dengue mosquito vector, Aedes aegypti, and virus (DENV) are also sensitive to climate variability and climate change (Hsieh and Chen, 2009), as temperature, humidity and precipitation influence mosquito biology, abundance and habitat and the virus replication speed, with increased dengue incidence during warmer and wetter seasons 
(Johansson et al., 2009). Temperature has a significant impact on dengue epidemiology, influencing both the population dynamics of Ae. aegypti and the development of the virus within the mosquito (the Extrinsic Incubation Period, EIP). Below $13^{\circ} \mathrm{C}$, mosquito eggs will usually not hatch and any larva will not complete their development (Christophers, 1960). Adult mosquito survival is also influenced by temperature and is constrained between lower $\left(4^{\circ} \mathrm{C}\right)$ and upper $\left(43^{\circ} \mathrm{C}\right)$ temperature limits. Many studies on EIP have shown that viral development within the mosquito accelerates with increasing temperature (e.g. Tjaden et al., 2013). The consequence of this is that the mosquito can become infectious faster, enabling onward transmission of the virus before mosquito mortality; an increase of only a few ${ }^{\circ} \mathrm{C}$ can therefore potentially lead to a substantial increase in force of infection. The association of rainfall with mosquito bionomics is more complex, particularly because of the adaptation of Ae. aegypti to a domesticated niche, where the mosquitoes use manmade breeding sites, which confounds any increased availability of natural breeding sites created by rain (Padmanabha et al., 2010; Scott et al., 2000). Therefore, the association is very dependent on the local extent of man-made breeding sites. More general non-linear effects of rainfall on mosquito density will also apply, such as larval wash-out and increased adult mortality following heavy rain. Finally, rainfall will have an indirect impact via its cooling effect on ambient temperature. For these reasons, the associations with rainfall tend to be site-specific with respect to mosquito densities and the relationship between mosquito density and dengue incidence itself is weak because of other behavioural traits, such as frequent multiple host feeding.

Many studies have found associations between climatic factors and dengue transmission (see (Naish et al., 2014; Thai and Anders, 2011) for a review). However, modelling approaches and methods to account for climate factors within the model vary considerably, which could lead to differential results regarding the relationships and time lags between climatic factors and dengue relative risk. Typically, the most significant time lags between temperature/precipitation and dengue are found to be around 1-2 months (Arcari et al., 2007; Cheong et al., 2013; Descloux et al., 2012; García et al., 2011; Gharbi et al., 2011; Gomes et al., 2012; Jeefoo et al., 2010; Lowe et al., 2011; Wu et al., 2007), although some studies report lags of around 3-4 months (Bi et al., 2001; Chen et al., 2012; Depradine and Lovell, 2004; Yu et al., 2011) .

Among one of the most affected regions, Thailand provides a very detailed and highly exhaustive dengue surveillance and mosquito control system, with datasets of reported cases for more than three decades. Dengue has been endemic in the country since 1958, with co-circulation of all four DENV serotypes. In most of the regions where serotype identification has been performed, two or 
three serotypes are found at the same time in the same area (Anantapreecha et al., 2004). Meanwhile, during epidemic periods the relative prevalence of the serotypes varies (Muttitanon et al., 2004). Dengue remains a disease of children and young adults in Thailand, with most cases occurring in individuals aged between 5 years and 24 years, who represent one third of the population (Limkittikul et al., 2014). The incidence rate appears to be declining from its peak in the 1970s and 1980s, but remains high at 20 per 1,000 for children $<15$ years old (Wichmann et al., 2011). The small temporal decline has been linked to a reduced estimated force of infection and the changing demography (reduced birth and death rates) may have contributed to this (Cummings et al., 2009). However, there exist no extensive data on seroprevalence and the majority of infections are inapparent with no clinical presentation (Grange et al., 2014).

In Thailand, dengue transmission occurs throughout the year, but there exists a marked cyclical pattern associated with the seasonal change in climate (Gubler, 1998), as in all Southern Asian countries. The seasonal peak in the numbers of cases is between May and September and coincides with the southwest monsoon season. The strength of the monsoon season is largely dependent on the local land-sea thermal contrast, with preconditioning by the premonsoon air temperatures over land playing a key role. The El Niño Southern Oscillation (ENSO) can modulate Thailand's rainfall regime, with El Niño (La Niña) events corresponding with low (high) rainfall seasons (Chen et al., 2002; Singhrattna et al., 2005). ENSO has been identified as a potential driver of dengue in Thailand, via its impact on local climate conditions (Cazelles et al., 2005). Campbell et al., (2013) demonstrated the complexity of the association between local climatic variables and dengue dynamics in Thailand with temperature found to define a viable range for dengue transmission (with $80 \%$ of severe dengue cases occurring when mean temperature was $27-29.5^{\circ} \mathrm{C}$ ) while humidity amplifies the potential within that range.

In order to control the spread of dengue and prepare for epidemics, decision support systems are required that take into account the multiple factors that contribute to increased dengue risk. Due to availability of seasonal climate forecasts that predict the average climate conditions for forthcoming months/seasons in both time and space, there is an opportunity to incorporate precursory climate information in a dengue decision support system to aid epidemic planning months in advance. In this paper we present a flexible spatio-temporal Bayesian modelling approach for dengue in Thailand to assess the potential use of climate information in a dengue decision support system. Monthly cases of dengue in the 76 provinces of Thailand for the period 1982-2013 are modelled in a hierarchical framework, which can allow for non-linearity in climate-dengue associations. In order 
to quantify unknown or unmeasured dengue risk factors, we use spatio-temporal random effects. This helps quantify the extent to which variations in climate are associated with dengue relative risk and assess whether climate information could significantly contribute to a dengue early warning system.

\section{Methods}

\subsection{Data}

\subsubsection{Dengue data}

Dengue is a notifiable disease in Thailand and data from all provinces exist from the beginning of the 1980s at the Ministry of Public Health of Thailand in Bangkok. From 2003 to the present, the reported data from the national surveillance system (DF, DHF, DSS using the 1997 WHO case definition) have been available on both the electronic and the hardcopy of the Weekly Bulletin of Epidemiology, Ministry of Public Health of Thailand (http://www.boe.moph.go.th/). Despite the unknown degree of under-reporting, this national surveillance system is thought to provide a good estimation, albeit underestimated, of the real disease burden in the country (Wichmann et al., 2011).

In this study, we have used aggregated monthly severe cases (DF+DHF+DSS) from published sources (Cazelles et al., 2005; Cummings et al., 2004; Nagao and Koelle, 2008) and the Weekly Bulletin of Epidemiology (http://www.boe.moph.go.th/), for the period 1982-2013 for 76 provinces in Thailand. As these different datasets have common, overlapping time periods, we compared reported cases and found that for these common periods, the values are quasi-identical. Details about these datasets, and more generally on the dengue cases data available in Thailand, can be found elsewhere (Aguiar et al., 2014).

Demography data was obtained from population census from 1980, 1990, 2000 and 2010 (from different web pages http://web.nso.go.th/en/census/poph/cen_poph.htm and http://www.statoids.com/uth.html). Since 2010, the tables in the Weekly Bulletin of Epidemiology give both numbers of cases and estimated census (see Fig. 1). 
ตารางที่ 3 จำนวนผู้ป่วยและตายสงสัยด้วยโรคไข้เลือดออก จำแนกรายเดือนตามวันเริ่มป่วย รายจังหวัด ประเทศไทย ปี พ.ศ. 2556 (30 ธันวาคม $2555-5$ มกราคม 2556)

TABLE 3 Reported Cases and Deaths of Suspected Dengue fever and Dengue Hemorrhagic fever Under Surveillance by Date of Onset, by Province, Thailand,

2013 (December 30, 2012 - January 5, 2013)

\begin{tabular}{|c|c|c|c|c|c|c|c|}
\hline \multirow{2}{*}{ REPORTING AREAS ${ }^{* *}$} & \multicolumn{7}{|c|}{ DENGUE HEMORRHAGIC FEVER - TOTAL (DF+DHF+DSS) 2012} \\
\hline & OCT & NOV & DEC & TOTAL & TOTAL & \multirow{2}{*}{$\begin{array}{c}\text { CASE RATE } \\
\text { PER } 100000 \\
\text { POP. }\end{array}$} & \multirow{2}{*}{$\begin{array}{c}\text { CASE } \\
\text { FATALITY } \\
\text { RATE }(\%)\end{array}$} \\
\hline & C & C & c & C & D & & \\
\hline TOTAL & 9521 & 10115 & 7172 & 78063 & 80 & 121.83 & 0.10 \\
\hline CENTRAL REGION & 4251 & 4761 & 3291 & 32344 & 28 & 152.64 & 0.09 \\
\hline BANGKOK METRO POLIS & 1666 & 2260 & 1646 & 10029 & 6 & 176.73 & 0.06 \\
\hline ZONE 1 & 391 & 466 & 335 & 2617 & 3 & 68.41 & 0.11 \\
\hline NONTHABURI & 127 & 135 & 134 & 860 & 0 & 76.61 & 0.00 \\
\hline P.NAKORN S.AYUTTHAYA & 124 & 160 & 88 & 637 & 3 & 80.87 & 0.47 \\
\hline PATHUM THANI & 56 & 103 & 87 & 554 & 0 & 54.80 & 0.00 \\
\hline SARABURI & 84 & 68 & 26 & 566 & 0 & 91.22 & 0.00 \\
\hline ZONE 2 & 306 & 179 & 74 & 2254 & 1 & 172.99 & 0.04 \\
\hline ANG THONG & 31 & 27 & 16 & 273 & 0 & 96.11 & 0.00 \\
\hline CHAI NAT & 38 & 71 & 51 & 382 & 1 & 114.63 & 0.26 \\
\hline LOP BURI & 232 & 80 & 0 & 1567 & 0 & 207.24 & 0.00 \\
\hline SING BURI & 5 & 1 & 7 & 32 & 0 & 14.98 & 0.00 \\
\hline ZONE 3 & 435 & 383 & 233 & 4258 & 3 & 135.10 & 0.07 \\
\hline CHACHOENGSAO & 195 & 128 & 53 & 1555 & 1 & 228.89 & 0.06 \\
\hline NAKHON NAYOK & 17 & 5 & 6 & 125 & 0 & 49.25 & 0.00 \\
\hline PRACHIN BURI & 82 & 35 & 17 & 888 & 0 & 189.08 & 0.00 \\
\hline SA KAEO & 48 & 15 & 10 & 708 & 1 & 129.77 & 0.14 \\
\hline SAMUT PRAKAN & 93 & 200 & 147 & 982 & 1 & 81.61 & 0.10 \\
\hline ZONE 4 & 629 & 584 & 356 & 4796 & 4 & 141.36 & 0.08 \\
\hline KANCHANABURI & 172 & 120 & 59 & 1209 & 1 & 144.11 & 0.08 \\
\hline NAKHON PATHOM & 166 & 181 & 134 & 1210 & 1 & 139.71 & 0.08 \\
\hline RATCHABURI & 197 & 191 & 76 & 1734 & 2 & 205.77 & 0.12 \\
\hline SUPHAN BURI & 94 & 92 & 87 & 643 & 0 & 76.09 & 0.00 \\
\hline ZONE 5 & 332 & 335 & 233 & 2652 & 6 & 158.63 & 0.23 \\
\hline PHETCHABURI & 48 & 53 & 34 & 682 & 0 & 146.33 & 0.00 \\
\hline PRACHUAP KHIRI KHAN & 48 & 34 & 25 & 429 & 2 & 83.70 & 0.47 \\
\hline SAMUT SAKHON & 200 & 222 & 146 & 1297 & 1 & 259.87 & 0.08 \\
\hline SAMUT SONGKHRAM & 36 & 26 & 28 & 244 & 3 & 125.72 & 1.23 \\
\hline ZONE 9 & 492 & 554 & 414 & 5738 & 5 & 211.32 & 0.09 \\
\hline CHANTHABURI & 62 & 66 & 27 & 1236 & 0 & 239.14 & 0.00 \\
\hline CHON BURI & 228 & 237 & 162 & 1821 & 4 & 136.03 & 0.22 \\
\hline RAYONG & 172 & 230 & 209 & 2278 & 1 & 357.20 & 0.04 \\
\hline TRAT & 30 & 21 & 16 & 403 & 0 & 181.52 & 0.00 \\
\hline SOUTHERN REGION & 1273 & 1907 & 1832 & 13072 & 18 & 137.35 & 0.14 \\
\hline ZONE 6 & 551 & 748 & 788 & 4989 & 9 & 140.88 & 0.18 \\
\hline CHUMPHON & 76 & 61 & 85 & 906 & 1 & 184.08 & 0.11 \\
\hline NAKHON SI THAMMARAT & 265 & 299 & 275 & 1883 & 5 & 123.39 & 0.27 \\
\hline PHATTHALUNG & 83 & 209 & 224 & 948 & 0 & 185.50 & 0.00 \\
\hline SURAT THANI & 127 & 179 & 204 & 1252 & 3 & 123.71 & 0.24 \\
\hline ZONE 7 & 207 & 281 & 251 & 3639 & 2 & 195.92 & 0.05 \\
\hline KRABI & 113 & 148 & 110 & 1817 & 0 & 414.80 & 0.00 \\
\hline PHANGNGA & 21 & 33 & 72 & 523 & 0 & 205.15 & 0.00 \\
\hline PHUKET & 10 & 29 & 14 & 363 & 1 & 102.59 & 0.28 \\
\hline RANONG & 6 & 9 & 9 & 213 & 1 & 115.86 & 0.47 \\
\hline TRANG & 57 & 62 & 46 & 723 & 0 & 115.36 & 0.00 \\
\hline ZONE 8 & 515 & 878 & 793 & 4444 & 7 & 124.37 & 0.16 \\
\hline NARATHIWAT & 42 & 70 & 64 & 413 & 0 & 55.26 & 0.00 \\
\hline PATTANI & 33 & 60 & 83 & 343 & 0 & 51.70 & 0.00 \\
\hline SATUN & 32 & 43 & 17 & 422 & 1 & 139.98 & 0.24 \\
\hline SONGKHLA & 357 & 649 & 576 & 2957 & 6 & 216.31 & 0.20 \\
\hline YALA & 51 & 56 & 53 & 309 & 0 & 62.58 & 0.00 \\
\hline
\end{tabular}

\begin{tabular}{|c|c|c|c|c|c|c|c|c|}
\hline \multicolumn{8}{|c|}{ DENGUE HEMORRHAGIC FEVER - TOTAL (DF+DHF+DSS) 2013} & \multirow{3}{*}{$\begin{array}{c}\text { POP. } \\
\text { DEC 31, } \\
2011\end{array}$} \\
\hline JAN & FEB & MAR & APR & TOTAL & TOTAL & \multirow{2}{*}{$\begin{array}{c}\text { CASE RATE } \\
\text { PER } 100000 \\
\text { POP. }\end{array}$} & \multirow{2}{*}{$\begin{array}{c}\text { CASE } \\
\text { FATALITY } \\
\text { RATE }(\%)\end{array}$} & \\
\hline C & C & C & $C$ & C & D & & & \\
\hline 176 & 0 & 0 & 0 & 198 & 0 & 0.31 & 0.00 & $64,076,033$ \\
\hline 57 & 0 & 0 & 0 & 61 & 0 & 0.29 & 0.00 & $21,189,388$ \\
\hline 35 & 0 & 0 & 0 & 35 & 0 & 0.62 & 0.00 & $5,674,843$ \\
\hline 9 & 0 & 0 & 0 & 9 & 0 & 0.24 & 0.00 & $3,825,693$ \\
\hline 9 & 0 & 0 & 0 & 9 & 0 & 0.80 & 0.00 & $1,122,627$ \\
\hline 0 & 0 & 0 & 0 & 0 & 0 & 0.00 & 0.00 & 787,653 \\
\hline 0 & 0 & 0 & 0 & 0 & 0 & 0.00 & 0.00 & $1,010,898$ \\
\hline 0 & 0 & 0 & 0 & 0 & 0 & 0.00 & 0.00 & 620,454 \\
\hline 5 & 0 & 0 & 0 & 5 & 0 & 0.38 & 0.00 & $1,302,970$ \\
\hline 4 & 0 & 0 & 0 & 4 & 0 & 1.41 & 0.00 & 284,061 \\
\hline 1 & 0 & 0 & 0 & 1 & 0 & 0.30 & 0.00 & 333,256 \\
\hline 0 & 0 & 0 & 0 & 0 & 0 & 0.00 & 0.00 & 756,127 \\
\hline 0 & 0 & 0 & 0 & 0 & 0 & 0.00 & 0.00 & 213,587 \\
\hline 0 & 0 & 0 & 0 & 0 & 0 & 0.00 & 0.00 & $3,151,672$ \\
\hline 0 & 0 & 0 & 0 & 0 & 0 & 0.00 & 0.00 & 679,370 \\
\hline 0 & 0 & 0 & 0 & 0 & 0 & 0.00 & 0.00 & 253,831 \\
\hline 0 & 0 & 0 & 0 & 0 & 0 & 0.00 & 0.00 & 469,652 \\
\hline 0 & 0 & 0 & 0 & 0 & 0 & 0.00 & 0.00 & 545,596 \\
\hline 0 & 0 & 0 & 0 & 0 & 0 & 0.00 & 0.00 & $1,203,223$ \\
\hline 7 & 0 & 0 & 0 & 11 & 0 & 0.32 & 0.00 & $3,392,715$ \\
\hline 1 & 0 & 0 & 0 & 3 & 0 & 0.36 & 0.00 & 838,914 \\
\hline 4 & 0 & 0 & 0 & 6 & 0 & 0.69 & 0.00 & 866,064 \\
\hline 0 & 0 & 0 & 0 & 0 & 0 & 0.00 & 0.00 & 842,684 \\
\hline 2 & 0 & 0 & 0 & 2 & 0 & 0.24 & 0.00 & 845,053 \\
\hline 0 & 0 & 0 & 0 & 0 & 0 & 0.00 & 0.00 & $1,671,831$ \\
\hline 0 & 0 & 0 & 0 & 0 & 0 & 0.00 & 0.00 & 466,079 \\
\hline 0 & 0 & 0 & 0 & 0 & 0 & 0.00 & 0.00 & 512,568 \\
\hline 0 & 0 & 0 & 0 & 0 & 0 & 0.00 & 0.00 & 499,098 \\
\hline 0 & 0 & 0 & 0 & 0 & 0 & 0.00 & 0.00 & 194,086 \\
\hline 1 & 0 & 0 & 0 & 1 & 0 & 0.04 & 0.00 & $2,715,260$ \\
\hline 0 & 0 & 0 & 0 & 0 & 0 & 0.00 & 0.00 & 516,855 \\
\hline 1 & 0 & 0 & 0 & 1 & 0 & 0.07 & 0.00 & $1,338,656$ \\
\hline 0 & 0 & 0 & 0 & 0 & 0 & 0.00 & 0.00 & 637,736 \\
\hline 0 & 0 & 0 & 0 & 0 & 0 & 0.00 & 0.00 & 222,013 \\
\hline 27 & 0 & 0 & 0 & 29 & 0 & 0.30 & 0.00 & $9,517,451$ \\
\hline 10 & 0 & 0 & 0 & 10 & 0 & 0.28 & 0.00 & $3,541,380$ \\
\hline 0 & 0 & 0 & 0 & 0 & 0 & 0.00 & 0.00 & 492,182 \\
\hline 4 & 0 & 0 & 0 & 4 & 0 & 0.26 & 0.00 & $1,526,071$ \\
\hline 6 & 0 & 0 & 0 & 6 & 0 & 1.17 & 0.00 & 511,063 \\
\hline 0 & 0 & 0 & 0 & 0 & 0 & 0.00 & 0.00 & $1,012,064$ \\
\hline 7 & 0 & 0 & 0 & 7 & 0 & 0.38 & 0.00 & $1,857,374$ \\
\hline 0 & 0 & 0 & 0 & 0 & 0 & 0.00 & 0.00 & 438,039 \\
\hline 7 & 0 & 0 & 0 & 7 & 0 & 2.75 & 0.00 & 254,931 \\
\hline 0 & 0 & 0 & 0 & 0 & 0 & 0.00 & 0.00 & 353,847 \\
\hline 0 & 0 & 0 & 0 & 0 & 0 & 0.00 & 0.00 & 183,849 \\
\hline 0 & 0 & 0 & 0 & 0 & 0 & 0.00 & 0.00 & 626,708 \\
\hline 10 & 0 & 0 & 0 & 12 & 0 & 0.34 & 0.00 & $3,573,101$ \\
\hline 0 & 0 & 0 & 0 & 0 & 0 & 0.00 & 0.00 & 747,372 \\
\hline 0 & 0 & 0 & 0 & 0 & 0 & 0.00 & 0.00 & 663,485 \\
\hline 0 & 0 & 0 & 0 & 0 & 0 & 0.00 & 0.00 & 301,467 \\
\hline 8 & 0 & 0 & 0 & 8 & 0 & 0.59 & 0.00 & $1,367,010$ \\
\hline 2 & 0 & 0 & 0 & 4 & 0 & 0.81 & 0.00 & 493,767 \\
\hline
\end{tabular}

\section{Figure 1: Example data table}

Weekly Epidemiological Surveillance Report Vol. 44 No. 1 : January 11, 2013. Source: http://www.boe.moph.go.th/ 
To compare dengue variations in time and space, dengue standardised morbidity ratios (SMR) (i.e. relative risk) were calculated as the ratio of observed to expected cases. Expected cases are calculated as the population at risk for dengue (obtained from yearly population estimates) multiplied by the overall ratio of dengue for the entire time period. For values of $\mathrm{SMR}=1$, the observed cases are equal to what is expected. If $\mathrm{SMR}=2$, the relative risk is doubled. Figure 2 shows the distribution of dengue relative risk, averaged over time for the 76 provinces across Thailand and averages in space for the period 1982-2013. Large epidemics occurred in the summer months of 1987, 1990, 1997, 1998, 2001, 2010 and 2013.
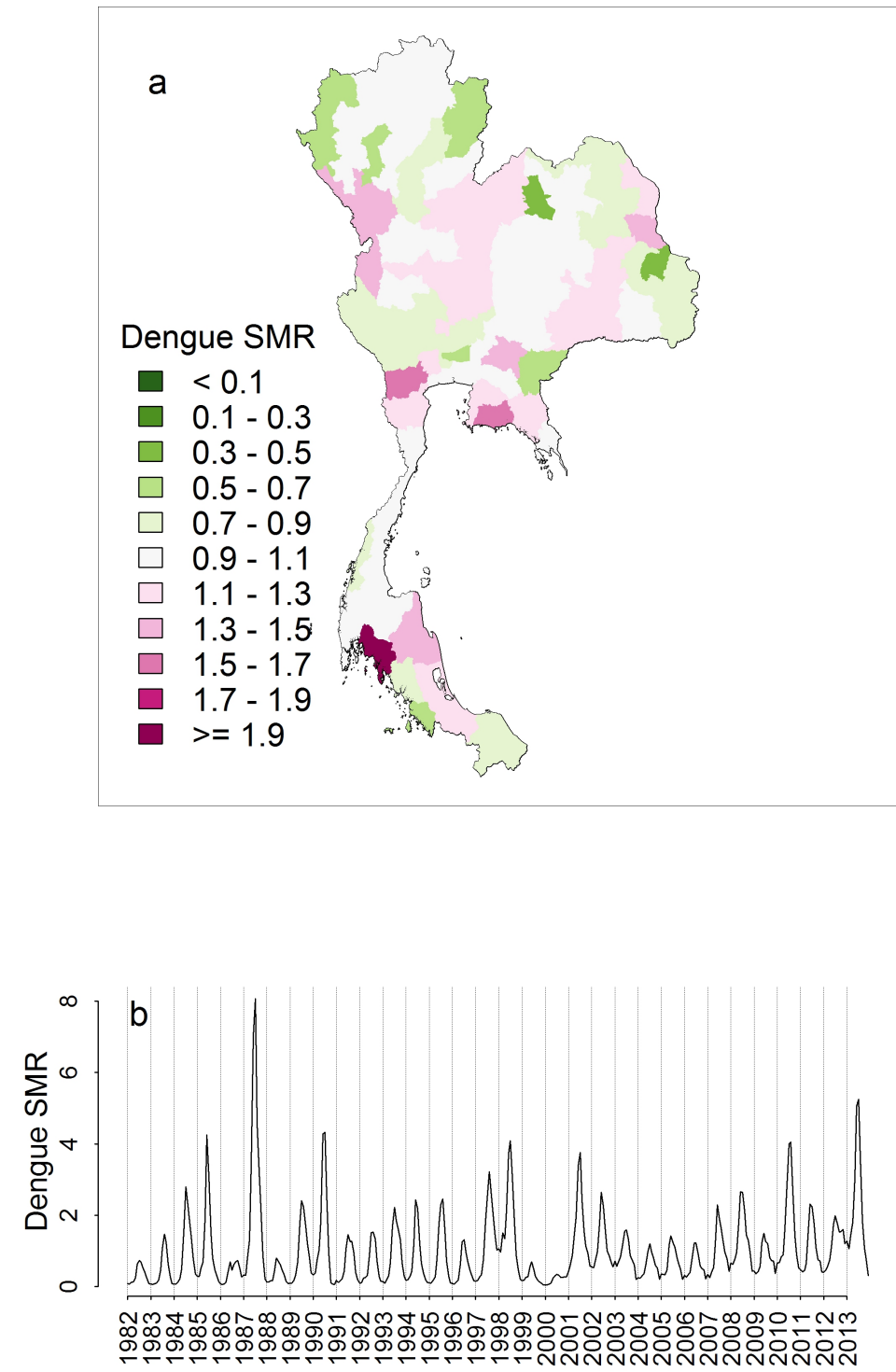

Figure 2: Spatial and temporal distribution of dengue relative risk

(a) Spatial and (b) temporal distribution of dengue relative risk (SMR) for the 76 provinces of Thailand, averaged over the period 1982-2013. 


\subsubsection{Meteorological data}

Precipitation and temperature data (minimum and maximum) was obtained from the Climatic Research Unit (CRU) TS 3.22 time series datasets, calculated on high-resolution $(0.5 \times 0.5$ degree $)$ grids, based on an archive of monthly mean meteorological variables provided by more than 4000 weather stations distributed around the world (Harris et al., 2014). These data were extracted for 704 grid boxes over Thailand and spatially interpolated to the 76 provinces. Figure 3 shows the annual mean and dispersion of monthly mean precipitation and mean temperature at the province level for the period 1982-2013. Figure 4 shows the monthly distribution of dengue relative risk (SMR), mean precipitation and mean temperature across Thailand for the period 1982-2013.
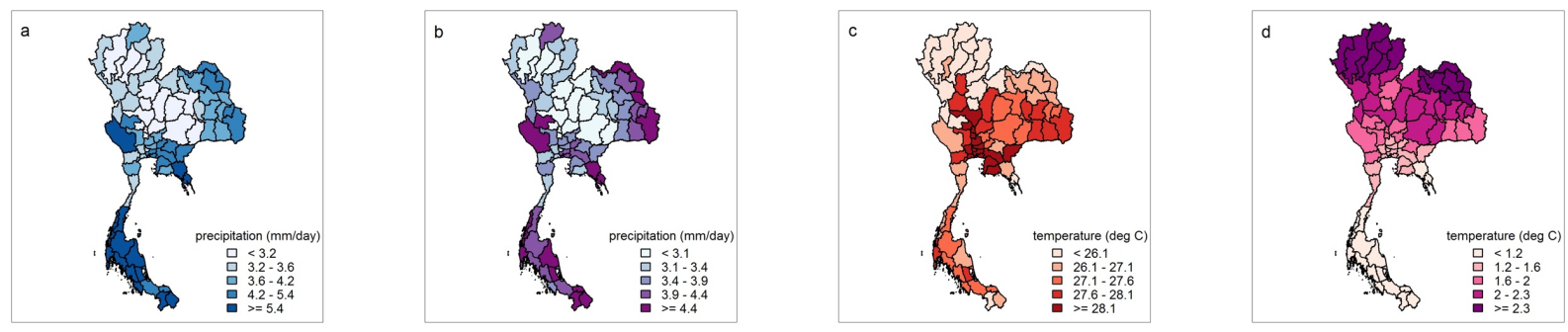

\section{Figure 3: Precipitation and temperature summary maps}

Annual monthly mean precipitation (a) mean and (b) dispersion (standard deviation) in $\mathrm{mm} /$ day and annual monthly mean temperature (a) mean and (b) dispersion (standard deviation) in degrees Celsius, for the period 1982-2013, for each province in Thailand. 

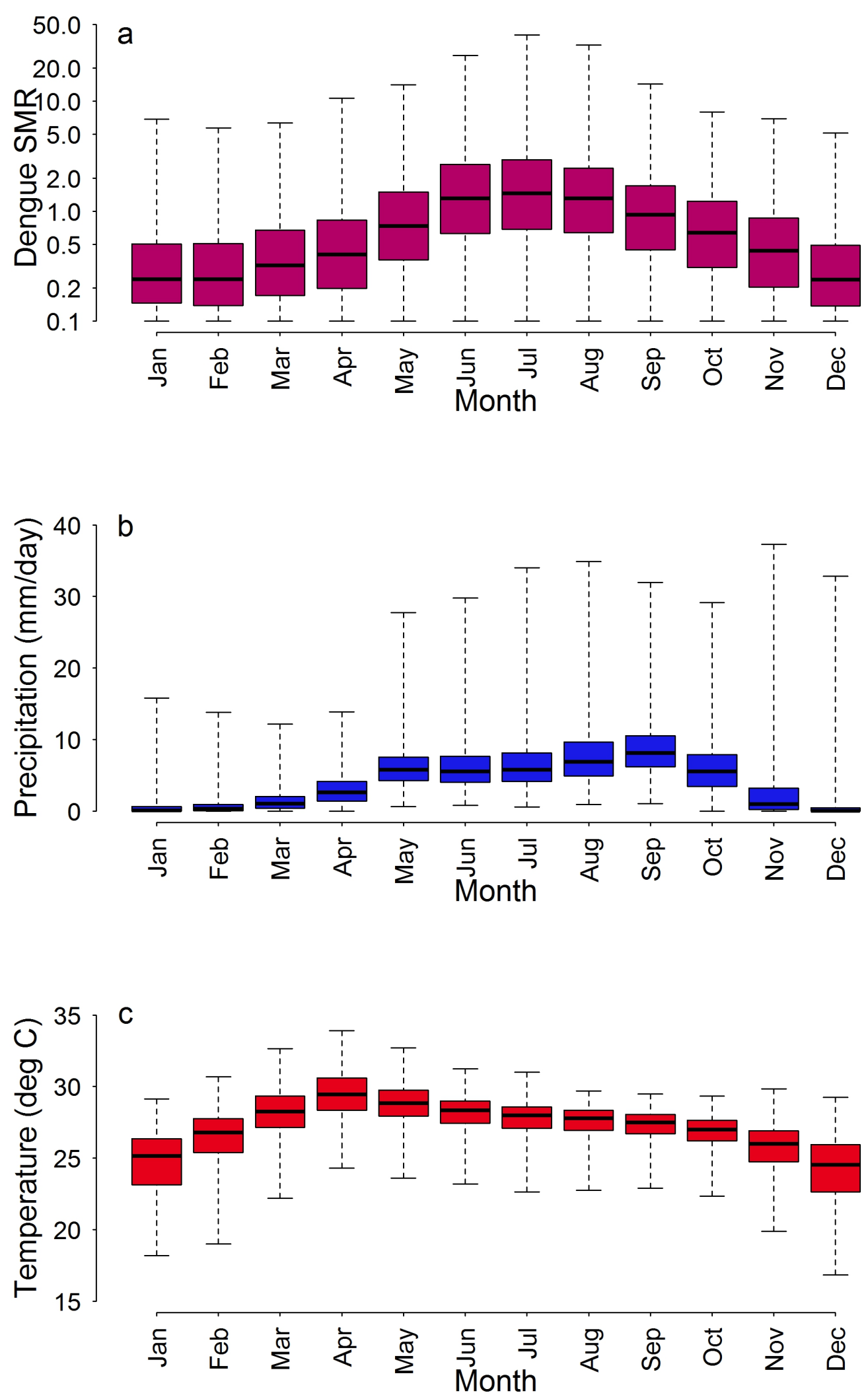

Figure 4: Annual cycle of dengue, precipitation and temperature across Thailand.

Distribution of (a) dengue relative risk (SMR), (b) average precipitation and (c) mean temperature for each calendar month (where 1 is January) across Thailand for the period 1982-2013. 


\subsection{Model formulation}

Generalized linear and additive mixed models (GLMM/GAMM) were formulated to assess the importance of climate variables as drivers of spatial variation and interannual variability in dengue transmission across Thailand. A negative binomial model was used to account for over-dispersion found in the dengue count data (extra-Poisson variation), where $y_{s t}$ is monthly dengue cases, $\mu_{s t}$ is mean cases, $e_{s t}$ is expected cases, and $\rho_{s t}$ is the dengue relative risk (Eqn. 1) (Lowe et al., 2013a; Stewart-Ibarra and Lowe, 2013). By including the expected number of cases of dengue as an offset, we estimated the relative risk (SMR) of dengue using a combination of spatio-temporal structures and linear and nonlinear functions of climate.

$$
\begin{gathered}
y_{s t} \sim \operatorname{NegBin}\left(\mu_{s t}, \kappa\right) \\
\log \mu_{s t}=\log e_{s t}+\log \rho_{s t}
\end{gathered}
$$

Eqn. 1

Using monthly climate and dengue data from 1982-2013 $(\mathrm{t}=1, \ldots, 384)$ for the 76 provinces $(s=1, \ldots, 76)$ of Thailand, we developed a set of models to understand the contribution of random temporal and structural effects and climate covariates to dengue relative risk $\left(\log \rho_{s t}\right)$. We started with a base model, the 'seasonal' model, that accounted for seasonality (an annual cycle) in dengue relative risk, which might be attributed to climate and/or seasonal population movements. This was incorporated via a first order autoregressive latent model, where dengue relative risk in one month is allowed to depend on the relative risk in the previous month. We then included spatial structure using a convolution prior that combined area-specific overdispersion and a neighbourhood dependency structure (see (Besag et al., 1995; Lowe et al., 2013a) for details), which we termed the 'seasonal-spatial' model. This model accounts for temporal dependency from one month to the next and similarities or differences between neighbouring provinces, but no interannual variability. The inclusion of random spatial and temporal structures in the model allowed us to account for unknown or unobserved confounding factors that influence the dengue transmission patterns, by introducing an extra source of variability into the model in a hierarchical framework. Model parameters were estimated within a Bayesian framework using Integrated Nested Laplace Approximation (INLA, www.r-inla.org) (Martins et al., 2013; Rue et al., 2009). INLA is a promising alternative to Markov Chain Monte Carlo (MCMC) methods, due to much shorter computational times. This approach provides a novel opportunity to perform model selection in a Bayesian framework, while accounting for underlying spatial and temporal dependency structures and linear or nonlinear 
functional forms. Such model selection would be extremely time and computing-intensive using MCMC estimation methods (Craig et al., 2007; Lowe et al., 2013b). Using the INLA framework, it was possible to determine optimum combinations of precipitation and temperature time lags, by fitting GLMMs and GAMMs, multiple times each, changing one lag at a time.

\subsection{Model assessment}

The goodness-of-fit of all models was assessed using the deviance information criterion (DIC) (Spiegelhalter et al., 2002) and an $\mathrm{R}_{\text {LR }}^{2}$ statistic for mixed effects models based on a likelihood ratio test between the candidate model (e.g. GLMM or GAMM) and an intercept only (null) model (Kramer, 2005; Magee, 1990). Smaller values of DIC indicate a better-fitting model, while $0 \leq \mathrm{R}_{\mathrm{LR}}^{2}$ $\leq 1$, with $\mathrm{R}_{\mathrm{LR}}^{2}=1$ corresponding to a perfect fit, and $\mathrm{R}_{\mathrm{LR}}^{2} \geq 0$ for any reasonable model specification. While information criteria can help decide which candidate model is best, they do not provide information about the amount of variation explained by the model. $\mathrm{R}_{\mathrm{LR}}^{2}$ is useful as a measure of goodness-of-fit and provides an intuitive measure of the ability of the model to account for the variation in the dependent variable.

The added value of including climate covariates in the model framework was assessed by calculating the root mean squared error (RMSE), a measure of the difference between modelled and observed values, over the 32 year time period, for each province (Lowe et al., 2013b). Smaller values of RMSE indicate a better fitting model. The difference between the RMSE for the model excluding climate information, i.e. the seasonal-spatial model and the RMSE for the model including climate as (a) linear (GLMM) and (b) nonlinear (GAMM) functions was calculated. Provinces with positive values $\left(\mathrm{RMSE}_{\text {noclimate }}-\mathrm{RMSE}_{\text {climate }}>0\right)$ indicate that accounting for climate variability improves the estimation of dengue relative risk in these places, as its inclusion results in a smaller difference between the modelled values and the observations, than using the seasonalspatial model alone.

\section{Results}

Table 1 shows model adequacy results for models of increasing complexity. First, we fitted a seasonal model, to account for the annual cycle in dengue. This model was found to explain $26 \%$ of the variation in dengue relative risk. This annual cycle in dengue is closely related to the annual cycle in precipitation and temperature (see Fig. 4). We then included location specific overdispersion and a neighbourhood dependency structure in the model, to account for unobserved 
confounding factors such as urbanisation and socio-economic disparities. This explained 32\%, an additional $6 \%$ of the variance. Using the seasonal-spatial model as a base, we then added different combinations of precipitation and mean temperature at time lags ranging from 0-12 months (169 different GLMMs/GAMMs were fitted). Figure 5 shows contour plots of of $\mathrm{R}_{\mathrm{LR}}^{2}$ for varying precipitation and mean temperature time lags when including these variables as (a) linear functions (GLMM) and (b) nonlinear functions (GAMM) (note: both maximum and minimum temperature were also tested, but mean temperature gave slightly higher $\mathrm{R}_{\text {LR }}^{2}$ values). Overall, slightly more variance in dengue relative risk was explained by using nonlinear functions of climate. For both the linear and nonlinear models, there was a peak in variance at all precipitation lags for temperature, lag 1. Given temperature lag 1, two maxima were found at precipitation lag 1 and lag 5. Given finding from previous literature and biological process understanding of the relationships between climate and dengue, a GLMM and GAMM with both precipitation and temperature lagged by one month were selected for further analysis (see Table 1). The linear and nonlinear climate models explained $39 \%$ and $40 \%$; an additional $7 \%$ and $8 \%$ respectively, in addition to the variation explained by seasonality and spatial structures.

Figure 6a shows the contribution to dengue relative risk for each month (seasonality), with a peak in July from the selected GAMM. Similarly, Figure $6 \mathrm{~b}$ shows the relative risk provided by different provinces, based on latent overdispersion and dependencies between neighbouring provinces, with an overall greater relative risk in the northwest of the country, along the border with Myanmar. Figure 7 shows the nonlinear relationships between precipitation/temperature and dengue relative risk from the selected GAMM. There is a general increase in relative risk as both variables increase, with increased uncertainty estimates for more extreme precipitation and temperature, which could inhibit dengue transmission. Note, that for the GLMM, the posterior median estimate for precipitation was 1.029 (95\% CI: 1.024, 1.035) and for temperature, 1.428 (95\% CI: 1.409, 1.447). This can be interpreted as an approximately $3 \%$ increase in dengue relative risk for a unit increase in precipitation and a $40 \%$ increase in dengue relative risk for a unit increase in temperature.

Figure 8 shows the added value of including climate information in addition to the seasonal-spatial model terms. When including climate as linear covariates, the modelled dengue relative risk is closer to observed values for $57 \%$ of the Thai provinces. When climate factors are modelling as nonlinear functions, this proportion increases to $79 \%$. The added value of climate information overlays the road network and elevation in the country. Climate appears to provide added value in 
provinces located in highland areas and some provinces located on the border with Malaysia, Cambodia, Laos and Myanmar.

Table 1: Goodness-of-fit results

Models are ranked by the deviance information criterion (DIC) and a likelihood ratio $\mathrm{R}_{\mathrm{LR}}^{2}$ statistic.

Model

Seasonal

(autocorrelated annual cycle)

\section{Seasonal-spatial}

$(\ldots+$ spatial structure $)$

\section{Climate-linear}

$(\ldots+$ rainfall, lag $1+$ temperature, lag 1$)$

\section{Climate-nonlinear}

$(\ldots+$ rainfall, lag $1+$ temperature, lag 1$)$

\section{Relative risk log}

$\log \rho_{\mathrm{st}}=\alpha+\omega_{\mathrm{t}^{\prime}(\mathrm{t})}$

278963.2

0.26

$\log \rho_{\mathrm{st}}=\alpha+\omega_{\mathrm{t}^{\prime}(\mathrm{t})}+\varphi_{\mathrm{s}}+v_{\mathrm{s}}$

276685.9

0.32

$\log \rho_{\mathrm{st}}=\alpha+\omega_{\mathrm{t}^{\prime}(\mathrm{t})}+\varphi_{\mathrm{s}}+\mathrm{v}_{\mathrm{s}}+\beta_{1} x_{1 \mathrm{st}-1}+\beta_{2} x_{2 \mathrm{st}-1}$

$\log \rho_{\mathrm{st}}=\alpha+\omega_{\mathrm{t}^{\prime}(\mathrm{t})}+\varphi_{\mathrm{s}}+v_{\mathrm{s}}+f\left(x_{1 \mathrm{st}-1}\right)+f\left(x_{2 \mathrm{st}-1}\right)$

273084.4

0.40
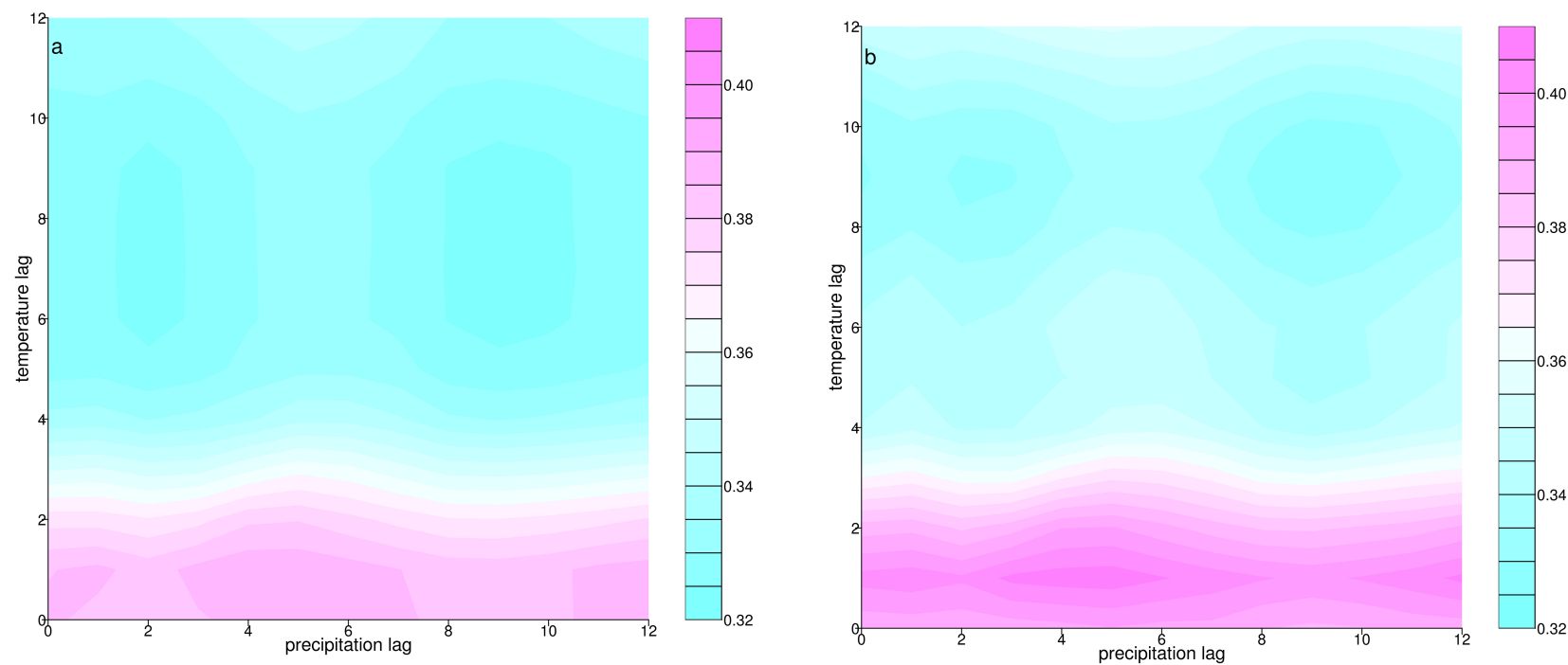

Figure 5: Optimum time lags for precipitation and temperature in explaining variation in dengue relative risk.

Surface of $\mathrm{R}_{\mathrm{LR}}^{2}$ at varying time lags in precipitation and temperature ( 0 to 8 months) for 81 models including (a) linear climate and (b) nonlinear climate functional forms. The most adequate model is taken as the model that gives the greatest $\mathrm{R}_{\mathrm{LR}}^{2}$, found with mean temperature, lagged by one month and mean precipitation, lagged by five months, for both linear (GLMM) and nonlinear (GAMM) models (results reported in Table 1). 

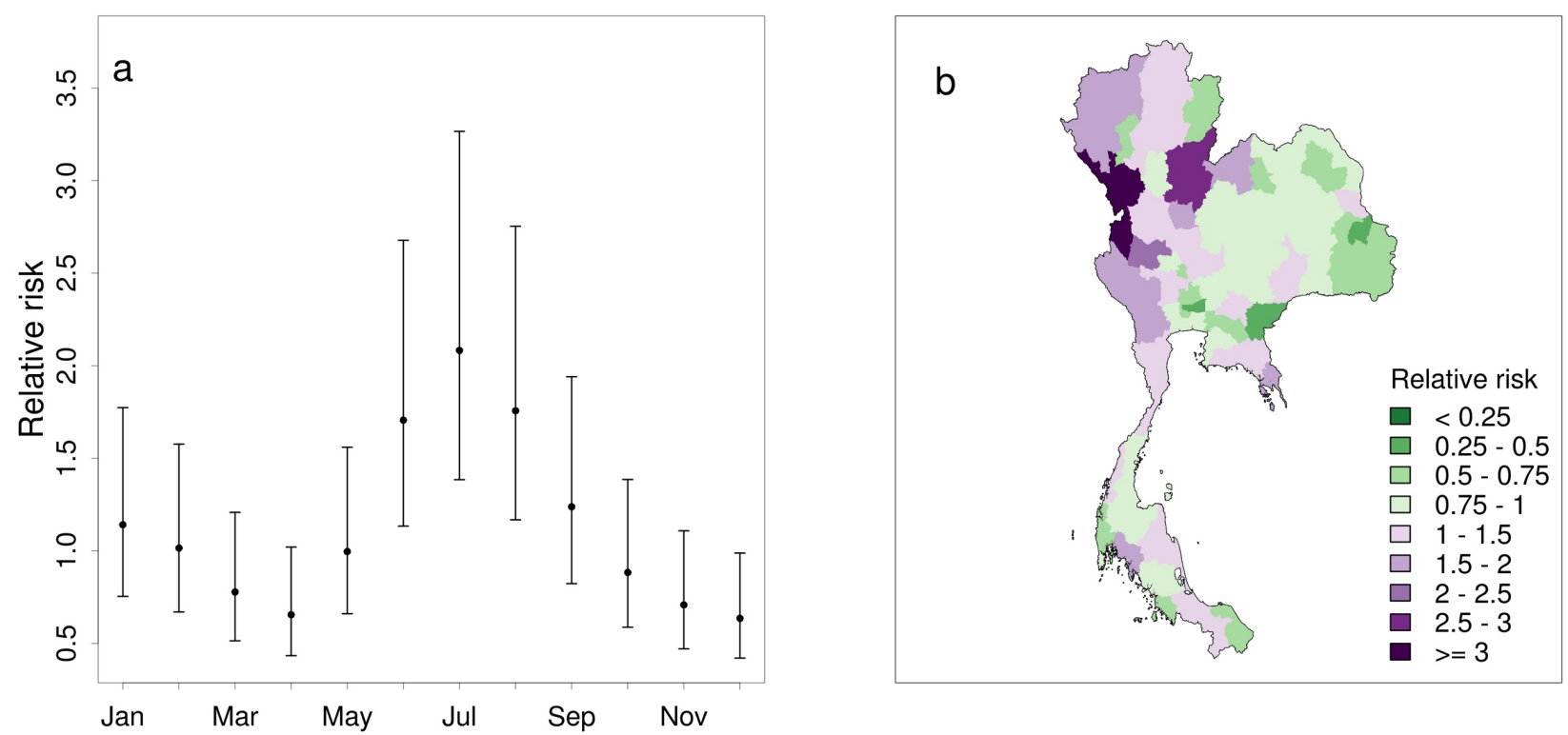

Figure 6: Seasonal and spatial contribution to dengue relative risk

Dengue relative risk contribution for (a) each month and (b) each province. Values greater (less) than one show \% increase (decrease).
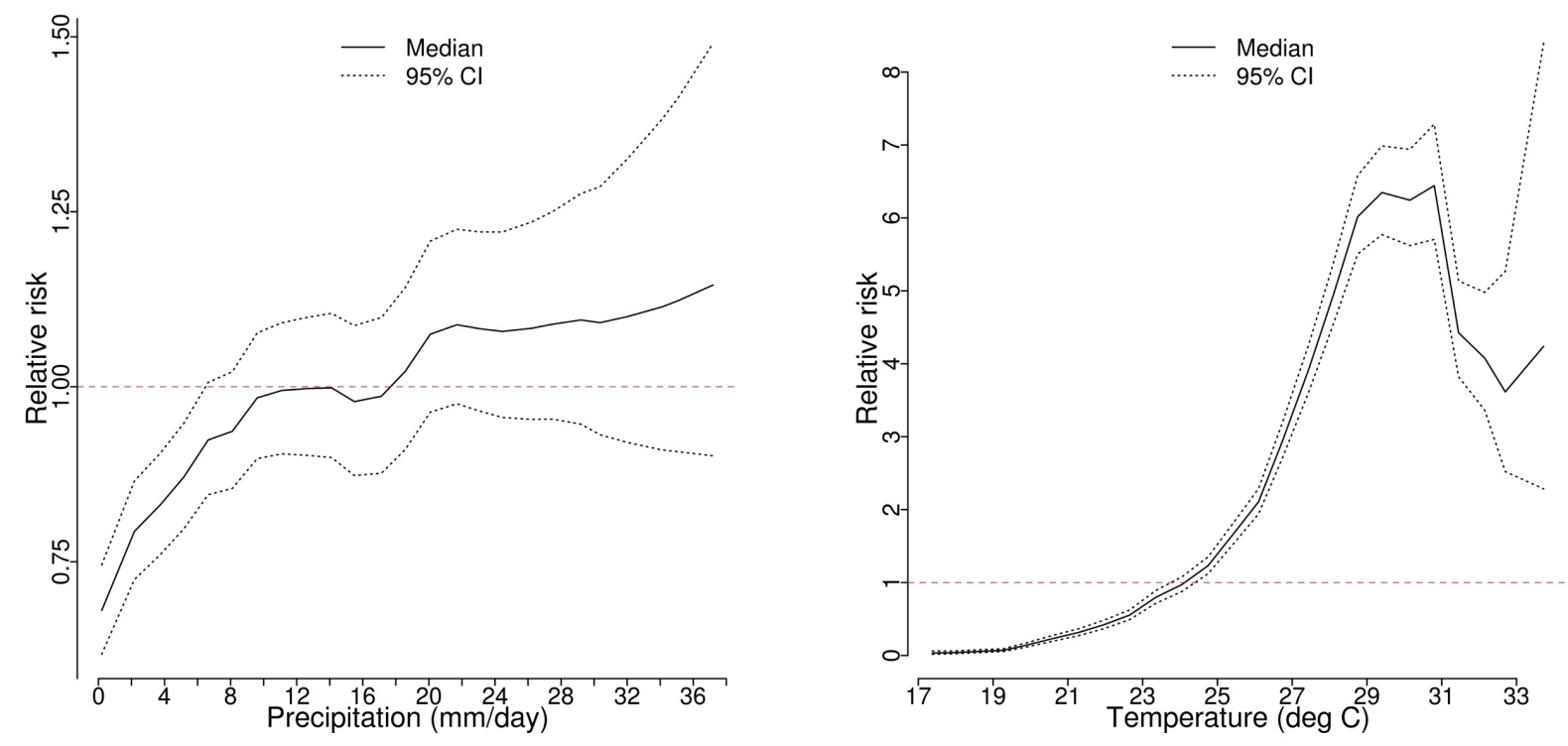

Figure 7: Effect of mean precipitation and temperature on next months dengue relative risk

The relative risk of dengue as functions of (a) mean precipitation and (b) mean temperature in the previous month. The solid line represents the median relative risk and the dotted lines, the $95 \%$ credible intervals. The red dashed line marks the point of no change in relative risk. 

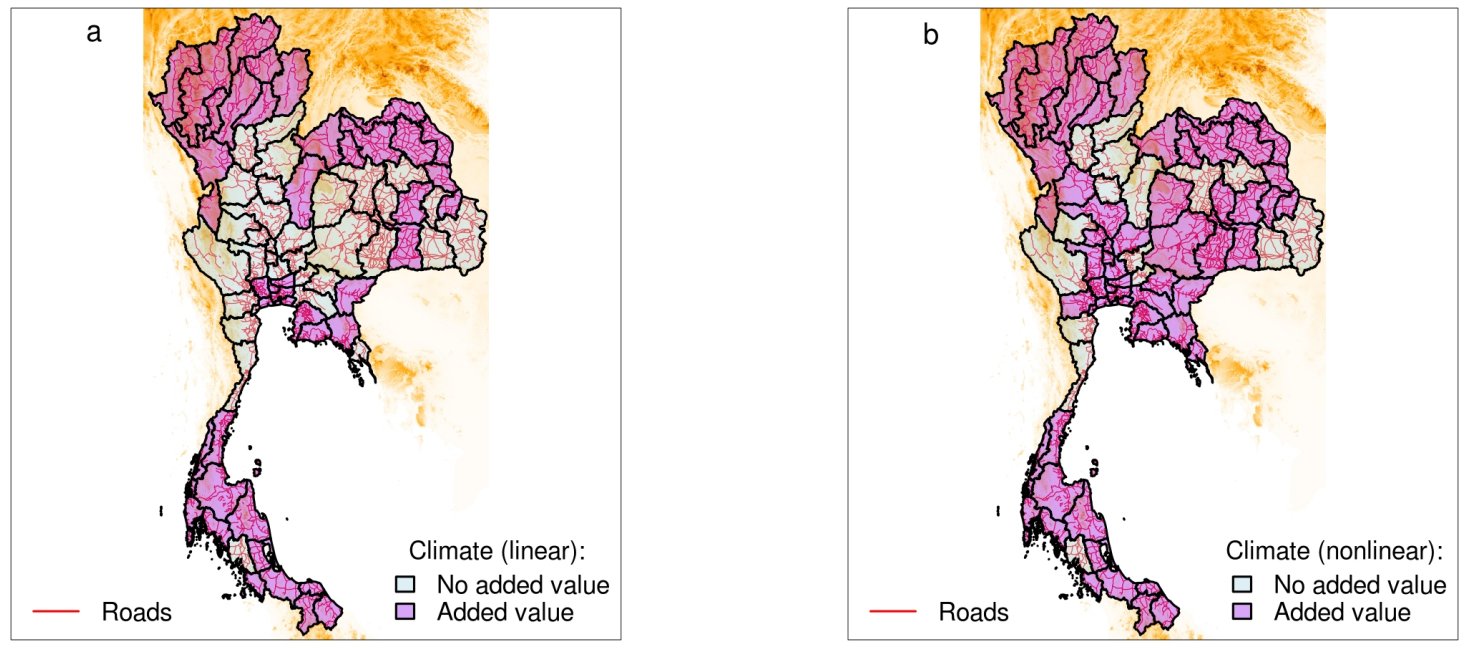

\section{Figure 8: Value added from using climate information to explain dengue relative risk variation.}

Difference between RMSE for the model excluding climate information and RMSE for the model including climate as (a) linear (GLMM) and (b) nonlinear (GAMM) functions. Provinces with positive values (purple) suggest that climate information improves the model in these areas. Provinces with negative values (light blue) suggest that climate information does not improve the model.

\section{Discussion}

In this study, the most adequate model of dengue relative risk, driven by climate factors, was determined using a novel Bayesian model selection framework and expert knowledge of dengue epidemiology. We quantified the additional variation explained by interannual climate variations at different time lags, above that provided by seasonal-spatial model. GLMMs and GAMMs with precipitation and temperature lagged by 1 month were selected for further investigation. The positive relationship between the clinical dengue relative risk and the temperature and precipitation the month before is consistent with what is classically known for the positive temperature relationship with developmental time of the mosquito and the virus within the mosquito at near optimal conditions (Christophers, 1960; Watts et al., 1987). Mosquito eggs will hatch in 2 days following submersion in water with warm ambient temperature and then progress through larval and pupal development to emerge as adults in as little as 6 days later. Mating and subsequent bloodfeeding on infectious hosts could generate infectious mosquitoes within 10 days. Thus, 
propitious ambient temperatures and sufficient rainfall generating breeding sites can lead to the rapid expansion of the infectious mosquito population and the infected human population within a month.

We also found a peak in model adequacy with temperature in the previous month, but precipitation 4-6 months previously. In addition, both the linear and nonlinear relationship between relative risk of clinical dengue and precipitation 4-6 months previously was negative. This feature is curious and deserves further investigation. One plausible explanation for this is the effect of homotypic or even heterotypic short-term immunity, where significant rainfall 4-6 months previously would lead to dengue transmission and hence deplenish the susceptible population. Consequently, the relative risk of clinical dengue 4-6 months later is reduced because of a reduced susceptible population, despite conditions propitious for dengue transmission. This may occur irrespective of the circulating serotype as homotypic immunity is believed to be life-long (Sabin, 1952) and heterotypic immunity is estimated to last from 3 months to a year (Reich et al., 2013; Sabin, 1952). The latter may not prevent infection, but rather reduce clinical disease (Endy et al., 2011; Grange et al., 2014; Sabin, 1952). Additionally, heavy rains can "wash-out" mosquito breeding sites, resulting in short-term population crashes. However, given the urban niche of Ae. aegypti, whilst wash-out may impact outdoor artificial/natural breeding sites, the majority of house proximal breeding sites (a predilection for Ae. aegypti) would likely remain relatively unaffected. Moreover, the delay of 4-6 months between the heavy rains and the drop in dengue incidence would require a considerable knock-on effect on mosquito densities, given that the life cycle is a matter of weeks. The long term effect of wash-out could, however, have longer term effects if there was a subsequent anomalously dry period that thus deprived mosquitoes of new breeding sites. But given the domesticated breeding habits of this mosquito, this is unlikely. The observed negative relationship could thus be the result of a direct negative effect on mosquito densities and an indirect effect on the susceptibility of the population to dengue disease.

Overall, a model including seasonal-spatial dependency structures alone accounted for $32 \%$ of the variance in dengue relative risk. When nonlinear functions of precipitation and temperature in the previous month were included, the variance explained increased to $40 \%$. The seasonality in dengue is mostly driven by the annual cycle in climatic factors, determined by the southwest monsoon. However, by accounting for interannual variations in precipitation and temperature in the previous month, an additional $8 \%$ of the variance in dengue relative risk is gained. Several previous studies 
that use climate to model dengue fever include an autoregressive time series component based on the idea that the current value of the time series can be explained as a function of past values (Hii et al., 2012; Tipayamongkholgul et al., 2009). However, these studies do not always quantify the contribution of an autoregressive lagged disease term compared to climate covariates to the variance explained by such a model. Elevated $\mathrm{R}^{2}$ values are often reported for models that include both climate and dengue in the previous time step, despite the fact that a large proportion of the variance is likely attributed to the dengue cases itself. It is advisable to test the added value of climate, without including these terms in the model, to gauge a more realistic idea of the added value provided by climate factors. Further, autoregressive terms with only one week or month lag offer little, if any, advance warning of an impending epidemic as the collation of such data may not be feasible in advance of the time period for which the forecast is valid. In practice, seasonal forecasts of the climate, with lead times up to several months ahead, would be the only feasible option to provide timely early warning of dengue epidemics (Lowe et al., 2014).

By comparing observed dengue to modelled dengue, using the seasonal-spatial model and the models including climate, we found that the inclusion of nonlinear functions of climate improved the model for $79 \%$ of the provinces. Provinces with no improvement indicate areas where more complex processes might influence dengue risk. Climate is likely to impact rural and urban areas differently while socio-economic conditions and vector control disparities will play in role in determining dengue risk. Ideally, other interannual signatures, such as serotype circulation and human mobility patterns would be included in the model.

\section{Conclusion}

Once accounting for spatial-temporal confounding factors, non-linear functions of temperature and precipitation were found to have a statistically significant positive contribution to the relative risk of dengue in the following month. Therefore, forecast climate information, which predicts anomalous climate patterns several months in advance, has potential utility in a dengue decision support system for Thailand. Taking advantage of climate forecast lead times, public health authorities will be better able to put into place community communication campaigns to increase public awareness of the ensuing epidemic season and encourage community based environmental hygiene to reduce the mosquito breeding sites. Dengue control can in principle be achieved when campaigns focus on larval source reduction (Gubler, 1998) and community participation has long been recognised as offering good potential as part of an integrated control programme (Townson et al., 2005) . 
However, maintaining active participation over a long period of time is a challenge and there is ample evidence that source reduction methods are often implemented poorly and consequently have little impact (Chadee et al., 2005; Hayes et al., 2003). Therefore, forecasts offer an evidence-base for activating community programs over a restricted period of time.

In addition, advanced warning would enable the implementation of a more effective surveillance system. Dengue epidemiology has a forest-fire signature with urban spreading of dengue virus via human mobility that is followed by local expansion. This suggests that the best way to tackle an epidemic is to rapidly target mosquitoes in the area around the dengue cases. Rapid detection of the first seasonal dengue cases and focused mosquito eradication should slow down the spread of the virus. Current fumigation methodologies are ineffective, in part because the insecticide dissipates rapidly with no or little residual action (Reiter, 2014). However, there are an increasing number of novel insecticidal techniques that offer potential for more effective vector control (Devine et al., 2009; Ritchie and Devine, 2013). An increased state of alert during a limited time period, made possible through climate-driven dengue forecasts, and rapid implementation of insecticidal methodologies that have residual action offer immense potential to help control dengue epidemics.

The model framework presented here is extremely flexible and could be applied to model spatiotemporal dengue variation in any geographical setting. This would facilitate between country comparisons of the impact of climate on dengue fever and contribute towards a more global approach to assessing the impact of climate variability and climate change on dengue risk.

\section{Declaration of interests}

We declare no competing interests.

\section{Acknowledgements}

The research leading to these results has received funding from the DENFREE project (grant agreement $n^{\circ} 282378$ ) funded by the European Commission’s Seventh Framework Research Programme. RL is grateful to the STEPHI project, Daniel Simpson and Harvard Rue for valuable training and technical support in using the R-INLA package. 


\section{References}

Aguiar, M., Paul, R., Sakuntabhai, A., and Stollenwerk, N. (2014). Are we modelling the correct dataset? Minimizing false predictions for dengue fever in Thailand. Epidemiol. Infect. 1-13.

Anantapreecha, S., Sa-ngasang, A., Sawanpanyalert, P., and Kurane, I. (2004). Annual changes of predominant dengue virus serotypes in six regional hospitals in Thailand from 1999 to 2002. Dengue Bull. 28, 1-6.

Arcari, P., Tapper, N., and Pfueller, S. (2007). Regional variability in relationships between climate and dengue/DHF in Indonesia. Singap. J. Trop. Geogr. 28, 251-272.

Besag, J., Green, P., Higdon, D., and Mengersen, K. (1995). Bayesian computation and stochastic systems. Stat. Sci. 3-41.

Bi, P., Tong, S., Donald, K., Parton, K.A., and Hobbs, J. (2001). Climate variability and the dengue outbreak in Townsville, Queensland, 1992-93. Environ. Health 1, 54.

Campbell, K.M., Lin, C., Iamsirithaworn, S., and Scott, T.W. (2013). The Complex Relationship between Weather and Dengue Virus Transmission in Thailand. Am. J. Trop. Med. Hyg. 89, 10661080.

Cazelles, B., Chavez, M., McMichael, A.J., and Hales, S. (2005). Nonstationary influence of El Niño on the synchronous dengue epidemics in Thailand. PLoS Med. 2, 313-318.

Chadee, D.D., Williams, F.L., and Kitron, U.D. (2005). Impact of vector control on a dengue fever outbreak in Trinidad, West Indies, in 1998. Trop. Med. Int. Health 10, 748-754.

Chen, J., Carlson, B.E., and Del Genio, A.D. (2002). Evidence for strengthening of the tropical general circulation in the 1990s. Science 295, 838-841.

Chen, M.-J., Lin, C.-Y., Wu, Y.-T., Wu, P.-C., Lung, S.-C., and Su, H.-J. (2012). Effects of extreme precipitation to the distribution of infectious diseases in Taiwan, 1994-2008. PloS One 7, e34651.

Cheong, Y.L., Burkart, K., Leitão, P.J., and Lakes, T. (2013). Assessing Weather Effects on Dengue Disease in Malaysia. Int. J. Environ. Res. Public. Health 10, 6319-6334.

Christophers, S. (1960). Aedes aegypti. The yellow fever mosquito. Its life history, bionomics and structure. Camb. Univ. Press Lond. 738 pp.

Craig, M.H., Sharp, B.L., Mabaso, M.L., and Kleinschmidt, I. (2007). Developing a spatialstatistical model and map of historical malaria prevalence in Botswana using a staged variable selection procedure. Int. J. Health Geogr. 6, 44.

Cummings, D.A., Irizarry, R.A., Huang, N.E., Endy, T.P., Nisalak, A., Ungchusak, K., and Burke, D.S. (2004). Travelling waves in the occurrence of dengue haemorrhagic fever in Thailand. Nature $427,344-347$.

Cummings, D.A., Iamsirithaworn, S., Lessler, J.T., McDermott, A., Prasanthong, R., Nisalak, A., Jarman, R.G., Burke, D.S., and Gibbons, R.V. (2009). The impact of the demographic transition on dengue in Thailand: insights from a statistical analysis and mathematical modeling. PLoS Med. 6, e1000139. 
Depradine, C., and Lovell, E. (2004). Climatological variables and the incidence of Dengue fever in Barbados. Int. J. Environ. Health Res. 14, 429-441.

Descloux, E., Mangeas, M., Menkes, C.E., Lengaigne, M., Leroy, A., Tehei, T., Guillaumot, L., Teurlai, M., Gourinat, A.-C., Benzler, J., et al. (2012). Climate-based models for understanding and forecasting dengue epidemics. PLoS Negl. Trop. Dis. 6, e1470.

Devine, G.J., Perea, E.Z., Killeen, G.F., Stancil, J.D., Clark, S.J., and Morrison, A.C. (2009). Using adult mosquitoes to transfer insecticides to Aedes aegypti larval habitats. Proc. Natl. Acad. Sci. 106, $11530-11534$.

Endy, T.P., Anderson, K.B., Nisalak, A., Yoon, I.-K., Green, S., Rothman, A.L., Thomas, S.J., Jarman, R.G., Libraty, D.H., and Gibbons, R.V. (2011). Determinants of inapparent and symptomatic dengue infection in a prospective study of primary school children in Kamphaeng Phet, Thailand. PLoS Negl. Trop. Dis. 5, e975.

García, C., García, L., Espinosa-Carreón, L., and Ley, C. (2011). Abundancia y distribución de Aedes aegypti (Diptera: Culicidae) y dispersión del dengue en Guasave Sinaloa, México. Rev. Biol. Trop. 59, 1609-1619.

Gharbi, M., Quenel, P., Gustave, J., Cassadou, S., Ruche, G.L., Girdary, L., and Marrama, L. (2011). Time series analysis of dengue incidence in Guadeloupe, French West Indies: forecasting models using climate variables as predictors. BMC Infect. Dis. 11, 166.

Gomes, A.F., Nobre, A.A., and Cruz, O.G. (2012). Temporal analysis of the relationship between dengue and meteorological variables in the city of Rio de Janeiro, Brazil, 2001-2009. Cad. Saude Publica 28, 2189-2197.

Grange, L., Simon-Loriere, E., Sakuntabhai, A., Gresh, L., Paul, R., and Harris, E. (2014). Epidemiological factors associated with high global frequency of inapparent dengue virus infections. Microb. Immunol. 5, 280.

Gubler, D.J. (1998). Dengue and dengue hemorrhagic fever. Clin. Microbiol. Rev. 11, 480-496.

Gubler, D.J. (2002). Epidemic dengue/dengue hemorrhagic fever as a public health, social and economic problem in the 21st century. Trends Microbiol. 10, 100-103.

Gubler, D.J. (2012). The economic burden of dengue. Am. J. Trop. Med. Hyg. 86, 743-744.

Guzman, M.G., Halstead, S.B., Artsob, H., Buchy, P., Farrar, J., Gubler, D.J., Hunsperger, E., Kroeger, A., Margolis, H.S., Martínez, E., et al. (2010). Dengue: a continuing global threat. Nat. Rev. Microbiol. 8, S7-S16.

Halstead, S.B. (2007). Dengue. The Lancet 370, 1644-1652.

Harris, I., Jones, P., Osborn, T., and Lister, D. (2014). Updated high-resolution grids of monthly climatic observations-the CRU TS3. 10 Dataset. Int. J. Climatol. 34, 623-642.

Hayes, J.M., García-Rivera, E., Flores-Reyna, R., Suárez-Rangel, G., Rodríguez-Mata, T., CotoPortillo, R., Baltrons-Orellana, R., Mendoza-Rodriguez, E., DE GARAY, B.F., Jubis-Estrada, J., et al. (2003). Risk factors for infection during a severe dengue outbreak in El Salvador in 2000. Am. J. Trop. Med. Hyg. 69, 629-633. 
Hii, Y.L., Zhu, H., Ng, N., Ng, L.C., and Rocklöv, J. (2012). Forecast of dengue incidence using temperature and rainfall. PLoS Negl. Trop. Dis. 6, e1908.

Hsieh, Y.-H., and Chen, C. (2009). Turning points, reproduction number, and impact of climatological events for multi-wave dengue outbreaks. Trop. Med. Int. Health 14, 628-638.

Jeefoo, P., Tripathi, N.K., and Souris, M. (2010). Spatio-temporal diffusion pattern and hotspot detection of dengue in Chachoengsao Province, Thailand. Int. J. Environ. Res. Public. Health 8, 5174.

Johansson, M.A., Cummings, D.A.T., and Glass, G.E. (2009). Multi-year variability and dengue El Niño Southern Oscillation, weather, and dengue incidence in Puerto Rico, Mexico, and Thailand: a longitudinal data analysis. PLoS Med. 6, e1000168, doi:10.1371/journal.pmed.1000168.

Kramer, M. (2005). R2 statistics for mixed models. In Proceedings of the Conference on Applied Statistics in Agriculture, pp. 148-160.

Limkittikul, K., Brett, J., and L'Azou, M. (2014). Epidemiological Trends of Dengue Disease in Thailand (2000-2011): A Systematic Literature Review. PLoS Negl. Trop. Dis. 8, e3241.

Lowe, R., Bailey, T.C., Stephenson, D.B., Graham, R.J., Coelho, C.A., Sá Carvalho, M., and Barcellos, C. (2011). Spatio-temporal modelling of climate-sensitive disease risk: Towards an early warning system for dengue in Brazil. Comput. Geosci. 37, 371-381.

Lowe, R., Bailey, T.C., Stephenson, D.B., Jupp, T.E., Graham, R.J., Barcellos, C., and Carvalho, M.S. (2013a). The development of an early warning system for climate-sensitive disease risk with a focus on dengue epidemics in Southeast Brazil. Stat. Med. 32, 864-883.

Lowe, R., Chirombo, J., and Tompkins, A.M. (2013b). Relative importance of climatic, geographic and socio-economic determinants of malaria in Malawi. Malar. J. 12, 416.

Lowe, R., Barcellos, C., Coelho, C.A., Bailey, T.C., Coelho, G.E., Graham, R., Jupp, T., Ramalho, W.M., Carvalho, M.S., Stephenson, D.B., et al. (2014). Dengue outlook for the World Cup in Brazil: an early warning model framework driven by real-time seasonal climate forecasts. Lancet Infect. Dis. 14, 619-626.

Magee, L. (1990). R 2 measures based on Wald and likelihood ratio joint significance tests. Am. Stat. 44, 250-253.

Martins, T.G., Simpson, D., Lindgren, F., and Rue, H. avard (2013). Bayesian computing with INLA: new features. Comput. Stat. Data Anal. 67, 68-83.

Muttitanon, W., Kongthong, P., Kongkanon, C., Yoksan, S., Nitatpattana, N., Gonzales, J., and Barbazan, P. (2004). Spatial and temporal dynamics of Dengue Hemorrhagic Fever epidemics, Nakhon Pathom province, Thailand, 1997-2001. Dengue Bull. 28, 35-43.

Nagao, Y., and Koelle, K. (2008). Decreases in dengue transmission may act to increase the incidence of dengue hemorrhagic fever. Proc. Natl. Acad. Sci. 105, 2238-2243.

Naish, S., Dale, P., Mackenzie, J.S., McBride, J., Mengersen, K., and Tong, S. (2014). Climate change and dengue: a critical and systematic review of quantitative modelling approaches. BMC Infect. Dis. 14, 167. 
Padmanabha, H., Soto, E., Mosquera, M., Lord, C., and Lounibos, L. (2010). Ecological links between water storage behaviors and Aedes aegypti production: implications for dengue vector control in variable climates. Ecohealth 7, 78-90.

Reich, N.G., Shrestha, S., King, A.A., Rohani, P., Lessler, J., Kalayanarooj, S., Yoon, I.-K., Gibbons, R.V., Burke, D.S., and Cummings, D.A. (2013). Interactions between serotypes of dengue highlight epidemiological impact of cross-immunity. J. R. Soc. Interface 10, 20130414.

Reiter, P. (2014). Surveillance and Control of Urban Dengue Vectors. In Dengue and Dengue Hemorrhagic Fever, pp. 481-518.

Ritchie, S.A., and Devine, G.J. (2013). Confusion, knock-down and kill of Aedes aegypti using metofluthrin in domestic settings: a powerful tool to prevent dengue transmission? Parasit. Vectors $6,1-9$.

Rue, H. avard, Martino, S., and Chopin, N. (2009). Approximate Bayesian inference for latent Gaussian models by using integrated nested Laplace approximations. J. R. Stat. Soc. Ser. B Stat. Methodol. 71, 319-392.

Sabin, A.B. (1952). Research on dengue during World War II. Am. J. Trop. Med. Hyg. 1, 30-50.

Scott, T.W., Amerasinghe, P.H., Morrison, A.C., Lorenz, L.H., Clark, G.G., Strickman, D., Kittayapong, P., and Edman, J.D. (2000). Longitudinal studies of Aedes aegypti (Diptera: Culicidae) in Thailand and Puerto Rico: blood feeding frequency. J. Med. Entomol. 37, 89-101.

Singhrattna, N., Rajagopalan, B., Kumar, K.K., and Clark, M. (2005). Interannual and interdecadal variability of Thailand summer monsoon season. J. Clim. 18, 1697-1708.

Spiegelhalter, D.J., Best, N.G., Carlin, B.P., and Van Der Linde, A. (2002). Bayesian measures of model complexity and fit. J. R. Stat. Soc. Ser. B Stat. Methodol. 64, 583-639.

Stewart-Ibarra, A.M., and Lowe, R. (2013). Climate and Non-Climate Drivers of Dengue Epidemics in Southern Coastal Ecuador. Am. J. Trop. Med. Hyg. 88, 971-981.

Thai, K.T., and Anders, K.L. (2011). The role of climate variability and change in the transmission dynamics and geographic distribution of dengue. Exp. Biol. Med. 236, 944-954.

Tipayamongkholgul, M., Fang, C.T., Klinchan, S., Liu, C.M., and King, C.C. (2009). Effects of the El Niño-Southern Oscillation on dengue epidemics in Thailand, 1996-2005. BMC Public Health 9, $1-15$.

Tjaden, N.B., Thomas, S.M., Fischer, D., and Beierkuhnlein, C. (2013). Extrinsic incubation period of dengue: Knowledge, backlog, and applications of temperature dependence. PLoS Negl. Trop. Dis. 7, e2207.

Townson, H., Nathan, M., Zaim, M., Guillet, P., Manga, L., Bos, R., and Kindhauser, M. (2005). Exploiting the potential of vector control for disease prevention. Bull. World Health Organ. 83, 942-947.

Watts, D., Burke, D., Harrison, B., Whitmire, R., and Nisalak, A. (1987). Effect of temperature on the vector efficiency of Aedes aegypti for dengue 2 virus. Am. J. Trop. Med. Hyg. 36, 143-152. 
Wichmann, O., Yoon, I.-K., Vong, S., Limkittikul, K., Gibbons, R.V., Mammen, M.P., Ly, S., Buchy, P., Sirivichayakul, C., Buathong, R., et al. (2011). Dengue in Thailand and Cambodia: an assessment of the degree of underrecognized disease burden based on reported cases. PLoS Negl. Trop. Dis. 5, e996.

Wu, P.-C., Guo, H.-R., Lung, S.-C., Lin, C.-Y., and Su, H.-J. (2007). Weather as an effective predictor for occurrence of dengue fever in Taiwan. Acta Trop. 103, 50-57.

Yu, H.-L., Yang, S.-J., Yen, H.-J., and Christakos, G. (2011). A spatio-temporal climate-based model of early dengue fever warning in southern Taiwan. Stoch. Environ. Res. Risk Assess. 25, 485-494. 